\title{
Loop Current Growth and Eddy Shedding Using Models and Observations: Analyses of the July 2011 Eddy-Shedding Event*
}

\author{
F.-H. XU \\ Princeton University, Princeton, New Jersey, and Ministry of Education Key Laboratory for Earth System Modeling, \\ and Center for Earth System Science, Tsinghua University, Beijing, China \\ Y.-L. CHANG \\ National Taiwan Normal University, Taipei, and National Central University, Zhongli, Taiwan \\ L.-Y. OEY \\ Princeton University, Princeton, New Jersey, and National Central University, Jhongli, Taiwan \\ P. HAMILTON \\ Science Applications International Corporation, Raleigh, North Carolina
}

(Manuscript received 1 August 2012, in final form 20 January 2013)

\begin{abstract}
Recent studies suggest that as the trade wind in the Caribbean Sea weakens from summer to fall, conditions become more favorable for the Loop Current in the Gulf of Mexico to shed an anticyclonic ring. This idea originated with observations showing a preference for more eddies from summer through fall, and it was confirmed using multidecadal model experiments. Here, the hypothesis is further tested by studying the dynamics of a specific eddy-shedding event in summer 2011 using a model experiment initialized with observation-assimilated reanalysis and forced by reanalysis wind from NCEP. Eddy shedding in July 2011 is shown to follow the weakening of the trade wind and Yucatan transport in late June. The shedding time is significantly earlier than can be explained based on reduced-gravity Rossby wave dynamics. Altimetry and model data are analyzed to show that empirical orthogonal function modes $1+2$ dominate the reducedgravity process, while higher modes contain the coupling of the Loop Current with deep layer underneath. The Loop's westward expansion at incipient shedding induces a deep cyclonic gyre in the eastern Gulf, embedded within which are small cyclones caused by the baroclinic instability of the strongly sheared current north of the Campeche Bank. The associated deep upwelling and upper-layer divergence from these cyclonic circulations accelerate eddy shedding.
\end{abstract}

\section{Introduction}

The Loop Current (LC; frequently used acronyms are presented in the appendix) is the dominant feature of circulation in the eastern Gulf of Mexico (GOM)

\footnotetext{
* Supplemental information related to this paper is available at the Journals Online website: http://dx.doi.org/10.1175/JPO-D-12-0138.s1.

Corresponding author address: L.-Y. Oey, Atmospheric and Oceanic Sciences Program, Princeton University, 300 Forrestal Road, Sayre Hall, Princeton, NJ 08544.

E-mail: lyo@princeton.edu
}

and the formation region of the Florida Current-Gulf Stream system. It is a component of the meridional overturning circulation, playing a key role in the global climate. The LC episodically sheds large warm-core eddies or rings (200-300 km wide, 500-1000 m deep) that generally propagate westward at approximately $2-5 \mathrm{~km} \mathrm{day}^{-1}$, with a maximum swirl speed of approximately $1.8-2 \mathrm{~m} \mathrm{~s}^{-1}$ [see Oey et al. (2005) for a review]. The LC and eddies affect every aspect of oceanography in the GOM, either directly or indirectly through the action of their smaller-scale subsidiaries.

The LC eddy shedding has been observed (e.g., Vukovich 1988; Sturges 1994; Sturges and Leben 2000) 
and simulated in several numerical models (Oey 1996; Candela et al. 2003; Ezer et al. 2003; Morey et al. 2003; Oey et al. 2003; Sheng and Tang 2003; Romanou et al. 2004; Lin et al. 2009; Chang and Oey 2011, 2012; Le Hénaff et al. 2012). Chang and Oey (2011) describe the ideal case of the Loop Current Cycle: an LC expansion, shedding, and retraction cycle. However, the LC eddy often detaches and reattaches to the LC several times before the final separation (Oey et al. 2003; Le Hénaff et al. 2012), suggesting a highly nonlinear and complex process.

The shedding of LC eddies can be understood as a competing imbalance between the mass influx through the Yucatan Channel, which grows the Loop, and the westward Rossby wave that tends to "peel" the eddy from the Loop; this will be referred to as the PichevinNof mechanism (Pichevin and Nof 1997; Nof 2005). The LC grows larger and deeper with a mass influx from the Yucatan Channel. When its Rossby radius $R_{o}$ (based on the Loop's upper-layer depth) reaches a certain size, the variation of the Coriolis parameter $f$ becomes significant (i.e., $\beta$ effects), and the westward eddy's speed (which is proportional to a long Rossby wave velocity of approximately $-\beta R_{o}^{2}$ ) exceeds the LC growth rate because of the mass influx. At this point, the LC eddy begins to detach. The idea may be extended to the case when the mass influx (i.e., Yucatan transport) varies slowly in time (longer than approximately 1-2 months), so that eddy shedding may also depend on this variation.

Molinari et al. (1977) were probably the first to suggest that the Yucatan transport has a seasonal cycle. Rousset and Beal (2010) found a strong seasonal transport signal from 5-yr shipboard acoustic Doppler current profiler (ADCP) observations. Using long-term, multidecadal model integrations forced by high-resolution reanalysis winds, Chang and Oey (2012, hereafter CO2012) showed that the Yucatan transport increases when the trade wind strengthens from spring to summer, and decreases when the trade wind weakens from summer to fall. They found significant correlations between the transport and wind stress and wind stress curl in the Caribbean Sea. Oey et al. (2003) showed that models forced by time-dependent wind produce strong Yucatan transport fluctuations, on the order of a few Svs ( $1 \mathrm{~Sv} \equiv$ $\left.10^{6} \mathrm{~m}^{3} \mathrm{~s}^{-1}\right)$ and larger. The authors' numerical experiments suggest that these wind-induced transport fluctuations influence the LC eddy-shedding periods. From satellite observations and models, CO2012 identify biannual preferences of LC eddy shedding in summer and winter; the model results indicate a strong dependence of eddy shedding on Yucatan transport. The biannual variation in the trade wind forces a corresponding biannual transport through the Yucatan Channel; as a consequence, the LC has a tendency to shed eddies as the wind weakens especially from summer to fall and, although less significant, also from winter to spring. Chang and Oey (2013, hereafter CO2013) found from 18-yr (1993-2010) satellite sea surface height (SSH) data (from which the annual steric cycle has been removed) a significant and asymmetric biannual variation of the growth and wane of LC: strong from summer to fall and weaker from winter to spring. The authors used a reduced-gravity (RG) model forced by biannually varying winds and found that a biannual signal is produced by vorticity and transport fluctuations in the Yucatan Channel because of the piling up and retreat of warm water in the northwestern Caribbean Sea forced by the wind. The Loop grows and expands with increased northward velocity and cyclonic vorticity of the Yucatan Current, and eddies are shed when these are near minima.

The Pichevin-Nof mechanism is fundamental for describing how an eddy can separate from the LC. While other factors such as upper-lower-layer coupling [including baroclinic instability (BCI)] do not determine eddy shedding, they may accelerate the timing when eddies are shed. Chérubin et al. (2006) treated the LC as a vortex and showed that it is baroclinically unstable; the nonlinear state consists of deep multipolar structures. Oey (2008) also showed that BCI can generate deep cyclones below $1000 \mathrm{~m}$. Deep cyclones have been observed [see review in Schmitz (2005)]. The upper-lower-layer (shallower and deeper than $1000 \mathrm{~m}$, respectively) mass coupling in the eastern Gulf (east of $90^{\circ} \mathrm{W}$ ) can also affect eddy shedding. Chang and Oey (2011) show that, at incipient shedding, the westward-extended LC forces a deep return flow into the eastern Gulf where the upper layer then becomes divergent while the lower layer becomes convergent. Similarly to the deep cyclones, the resulting upwelling in the eastern Gulf may accelerate eddy shedding.

In this study, we attempted 1) to test the hypothesis that eddy shedding may be caused by the weakening of the Caribbean Sea's trade wind by analyzing a specific 2011 event using the results obtained from a threedimensional (3D) numerical experiment initialized with data assimilation, and 2) to demonstrate that upperlower coupling accelerates the timing of eddy shedding using long-term satellite observations and $3 \mathrm{D}$ and $\mathrm{RG}$ numerical models.

Section 2 describes the methods. Section 3 analyzes the eddy-shedding event of July 2011. Section 4 examines upper-lower coupling which accelerates eddy shedding. Section 5 concludes the paper.

\section{Methods}

Two sets of model results are used; they are based on the Princeton Ocean Model (POM) for the western 
North Atlantic Ocean including the GOM (domain: $5^{\circ}-$ $55^{\circ} \mathrm{N}, 55^{\circ}-100^{\circ} \mathrm{W}$ ). Details of this system are documented in previous works; these are summarized in appendix 1 of the supplemental material. In the first set, we focus on a specific eddy-shedding event near the end of July 2011. We conduct a free-running model experiment that is driven by reanalysis wind from the National Centers for Environmental Prediction (NCEP), and that has been initialized with data assimilation approximately 2 months (15 May 2011) before the observed eddy-shedding event. The experiment is called "Exp. May15" (also "forecast" to emphasize that it is unconstrained by observations except at the initial time). In appendix 2 of the supplemental material, the initialization analysis is checked against satellite and in situ data. In the next section, the Exp.May15 is analyzed to study the hypothesis that eddy shedding is related to the weakening of the trade wind.

The Exp.May15 will be shown to yield an eddyshedding time that is earlier (i.e., accelerated shedding) than estimated from the Pichevin-Nof mechanism according to reduced-gravity Rossby wave dynamics. A second set of model experiments are therefore designed to explain the difference. Long-term free-running experiments are conducted using $3 \mathrm{D}$ and RG models based on POM. The 3D model results are from CO2012 where details may be found. The RG model has also been previously described (Chang and Oey 2010; CO2013). Both models have the same domain and resolution as Exp. May15, but they are forced by six-hourly, high-resolution $\left(0.25^{\circ} \times 0.25^{\circ}\right)$, cross-calibrated multi-platform (CCMP) winds from July 1987 through December 2009. The satellite SSH anomaly (SSHA; 1993-2011) data from Archiving, Validation, and Interpretation of Satellite Oceanographic data (AVISO) (http://www.aviso.oceanobs. $\mathrm{com} /$ ) are used for analysis only. Empirical orthogonal function (EOF) and LC cycle composite analyses (Chang and Oey 2011) are used to compare the satellite and model data and to show that upper-lower-layer coupling accounts for the accelerated shedding.

\section{Analyses of modeled Loop Current growth and eddy shedding}

In late July 2011, a large ring (diameter of approximately $300 \mathrm{~km}$ ) was observed separating from the LC, coincident with the weakening of the summer trade wind in that year. The event fits well with the conditions proposed in $\mathrm{CO} 2012$ that eddy shedding tends to occur following the weakening of the trade wind. Figure 1 shows modeled SSH and surface currents. Because of data assimilation, the initial position of the modeled Loop agrees well with AVISO. In the subsequent
6 weeks (16 May-27 June in Fig. 1), the observed Loop expands north-northwestward, which is well captured by the model. On 20 June, AVISO shows that an elliptic "ringlet" with a major axis of approximately $150 \mathrm{~km}$ and minor axis of approximately $75 \mathrm{~km}$ is shed, but the main portion of the LC continues to grow through mid-July. On 25 July, a large ring separates from the LC (not shown, but see Fig. A1 in the supplemental material). In the model, no ringlet is shed, but the modeled Loop continues to grow northwestward as in the observations through the first week of July, and a large ring (diameter of approximately $300 \mathrm{~km}$ ) is shed on 8 July 2011 . It is interesting that the modeled eddy-shedding time is approximately the midpoint between the two observed rings. Following their strong growths, both modeled and observed Loop Currents are poised to shed eddies. According to the hypothesis of CO2012, the growth is caused by a continued influx of Yucatan transport, which moreover is increasing because of an intensified Yucatan Current that is forced by a strengthening summer trade wind in the Caribbean Sea. The forecasted and observed dates of the shedding of the large eddies differ by approximately 2.5 weeks. ${ }^{1}$ However, their SSH fields match reasonably well up to incipient shedding. Here, we analyze the modeled results with the objective of understanding the relevant dynamics and forcing that can explain the eddy-shedding event in July 2011.

\section{Eddy shedding and its connection to Caribbean Trade Wind and Yucatan transport variations}

Figure 2 shows the SSH on 10 June from Exp.May15. This shows that both modeled and observed LC are well extended at this time. As the LC is fed by inflow through the Yucatan Channel, it grows to a sufficiently large size (diameter of approximately $200-300 \mathrm{~km}$ ). At some stage, it becomes sufficiently deep [upper-layer thickness $h(t)$ of approximately $500 \mathrm{~m}$ ] that $\beta$ effects become important. According to the Pichevin-Nof mechanism (Pichevin and Nof 1997; Nof 2005), the westward eddy velocity, which is proportional to the Rossby wave velocity $C_{i}=-\beta R_{o}^{2}$, where $R_{o}=\left\{\left[g^{\prime} h(t)\right]^{1 / 2}\right\} / f$ and $g^{\prime}$ is the reduced gravity, then exceeds the inflow growth rate, and a portion of the Loop's mass - that is, a warm eddy-is "peeled" westward. The $C_{i}$ is estimated at $26^{\circ} \mathrm{N}, 89.4^{\circ} \mathrm{W}$ (see Fig. 2), which is near the center of the

\footnotetext{
${ }^{1}$ The mismatch is not surprising; the eddy-shedding date is approximately $7-8$ weeks into the forecast horizon (initialized on 15 May), which is near the limit of modeled Loop Current predictability (Yin and Oey 2007). The forecast initialized on 1 July (Exp.Jul01) predicts the eddy-shedding date of 25 July in good agreement with AVISO (see appendix 2 in the supplemental material)
} 


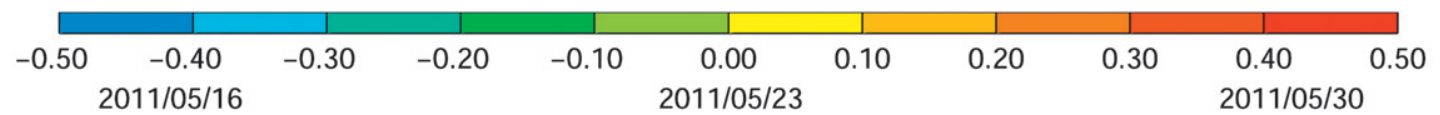
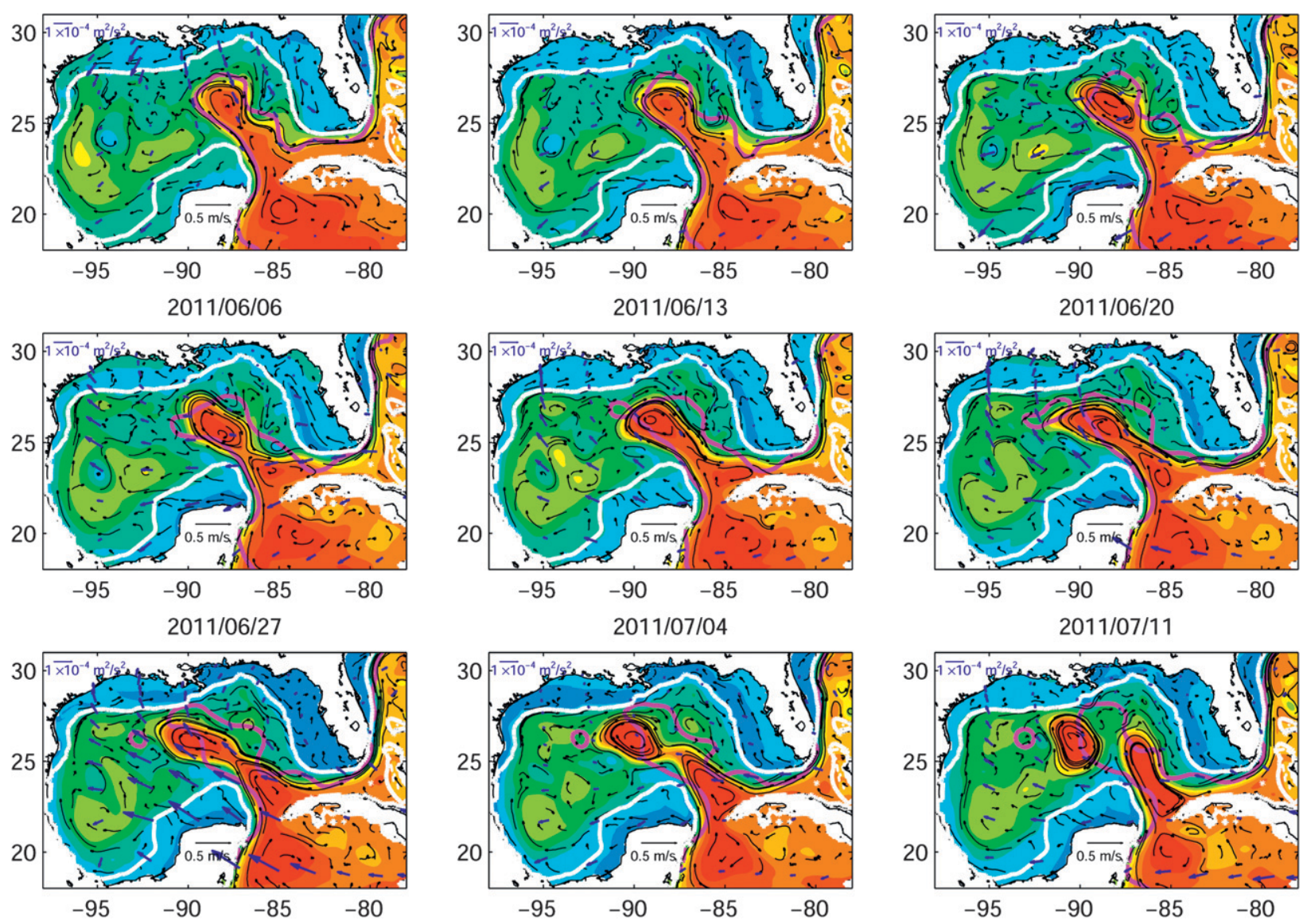

FIG. 1. SSH (background colors; $m$ ) and surface currents (black vectors; reference vector over Yucatan) shown every 7 days starting (top left) on 16 May for Exp.May15. Wind stresses (blue vectors; reference vector in top left corner of panel), 200-m isobaths (white contour), and SSH $=0$ from AVISO for comparison with the model (magenta line) are also provided. The model predicts eddy shedding on 8 Jul while AVISO shows the shedding of a small ring (a ringlet) on 20 Jun and a large ring on 25 Jul (not shown).

modeled Loop's warm-water mass during 8 June-8 July 2011, and its temporal variation is shown in Fig. 3c. The $-C_{i}$ increased from March to June, became maximum and nearly constant at approximately $0.05 \mathrm{~m} \mathrm{~s}^{-1}$ for the entire June, and then dropped rapidly in early July prior to eddy shedding. This maximum $-C_{i}$ agrees with the estimate of an eddy's speed by $\mathrm{CO} 2013$ based on the observed leading 2 EOFs, and corresponds to an effective $R_{o}$ of approximately $50 \mathrm{~km}$.

During 2011, the trade wind stress (Fig. 3a) strengthened from being very weak in mid-May to an approximate range of from $-5 \times 10^{-5}$ to $-4 \times 10^{-5} \mathrm{~m}^{2} \mathrm{~s}^{-2}$ during the first 2 weeks of June. The Yucatan transport (Fig. 3b) increased from a minimum of $27.2 \mathrm{~Sv}$ in mid-May to approximately a constant 29 Sv during the first 2 weeks of June. The wind then strengthened to $-10^{-4} \mathrm{~m}^{2} \mathrm{~s}^{-2}$ in late June before it rapidly weakened to $-0.4 \times 10^{-4} \mathrm{~m}^{2} \mathrm{~s}^{-2}$ in early July. By mid-August, the trade wind has further weakened to $-0.3 \times 10^{-4} \mathrm{~m}^{2} \mathrm{~s}^{-2}$. Correspondingly, the transport rapidly increased from mid-to-late June to a peak of approximately $33 \mathrm{~Sv}$, decreased to approximately $26 \mathrm{~Sv}$ in mid-July, and by midAugust had further weakened to approximately $23 \mathrm{~Sv}$. The increased wind and transport from May through June corresponds well with the rapid growth of the modeled (and observed) LC during the same period as described previously in Fig. 1. The zero-lag correlation coefficient between the daily zonal wind stress and $\mathrm{Yu}-$ catan transport is $-0.6(-0.75$ if the 10-day-running mean time series are used, both being above the $95 \%$ significance). Similarly large amplitudes of transport fluctuations have previously been documented in observations by Sheinbaum et al. (2002) and Rousset and Beal (2010), and in numerical models by Candela et al. 

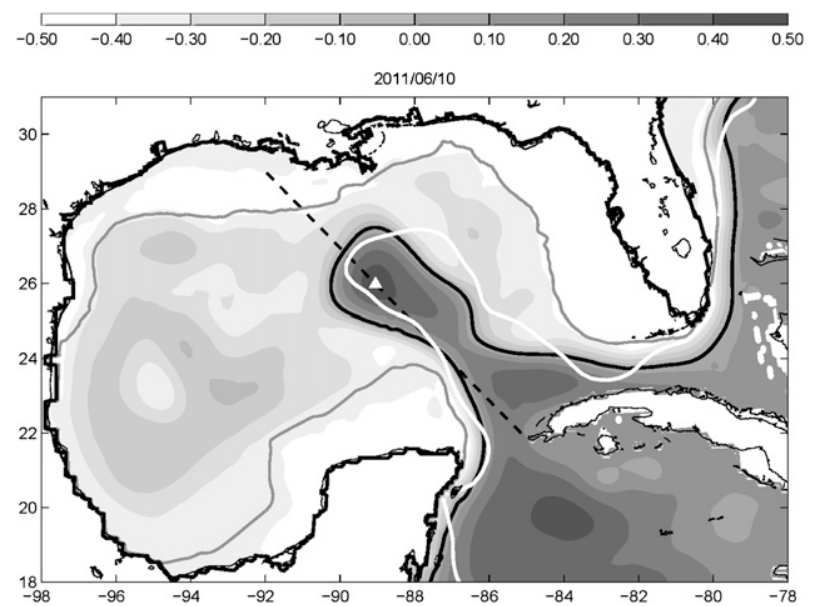

FIG. 2. The daily-averaged SSH (background grayscale, black contour is $\mathrm{SSH}=0 ; \mathrm{m}$ ) on 10 Jun from Exp.May15. The thick white contour indicates the $\mathrm{SSH}=0$ from AVISO satellite data. The black dashed line indicates the transect used to track the Loop Current's northern boundary (LCNB). The white triangle $\left(26^{\circ} \mathrm{N}\right.$, $\left.89.4^{\circ} \mathrm{W}\right)$ is where the Rossby wave speed $\left|C_{i}\right|$ is estimated.

(2003), Ezer et al. (2003), and Oey et al. (2003). The modeled transport values (Fig. 3b) also agree well with the seasonal minimum of Rousset and Beal (2010) of approximately $27.5 \mathrm{~Sv}$ in May and maximum of approximately $32.7 \mathrm{~Sv}$ in July.

The relation between trade wind stress and Yucatan transport agrees well with CO2012. The authors analyzed long-term (approximately 22 year) model runs forced by CCMP wind stress and found that the Yucatan transport peaks (weakens) at approximately the same time (maximum correlation was at a lag of about 1 month) as when the trade wind in the Caribbean Sea peaks (weakens). The transport is also negatively correlated with the wind stress curl in the Caribbean Sea. The authors concluded that following a period of intensified wind stress, hence also the wind stress curl and transport, during which the LC matures, the weakening of wind and Yucatan transport then provides a favorable condition for the separation of the LC eddy. While such a deterministic (rather than chaotic) view of the complex shedding process is not likely to hold in every case, the authors' extensive model experiments provide a statistically significant finding of preferential eddy shedding from approximately summer to fall and in late winter. CO2013 further tested this using an RG model as well as analysis of altimetry data. The satellite observations show an asymmetric LC growth and wane cycle, strong from summer to fall and weak from winter to spring, that is consistent with the trade wind and transport asymmetries described by CO2012; these facts suggest a dependency of the LC growth and eddy shedding on the forcing. In the present case, the weakening of the trade wind and Yucatan transport began at the end of June, when $\left|C_{i}\right|$ reached a maximum (Fig. 3c), and the wind continued to weaken through mid-August. An eddy was shed shortly after the wind and transport weakened, on 8 July.

The LC's northward extension has previously been found to be sensitive to the vorticity $\zeta$ of the inflowing Yucatan Current (CO2012, CO2013) consistent with Reid (1972). Input of cyclonic (or increasing) vorticity extends the Loop, while the Loop retracts with input of negative (or decreasing) vorticity. To test this, $\zeta$ is computed, following $\mathrm{CO} 2012$ at the western $50 \mathrm{~km}$ edge of the Yucatan Current in the upper $200 \mathrm{~m}$. The LC's northern boundary (LCNB) is also tracked along a southeast-northwest transect from the Yucatan Channel cutting across the Loop (see Fig. 2). The $\zeta / f$ and LCNB are plotted in Fig. 3d, which shows a gradual rise of both parameters from May through approximately 18 June when the Loop also grows (i.e., $-C_{i}$ increases, Figs. 1 and 3c). Thereafter both $\zeta / f$ and LCNB drop, and eddy shedding occurs as $\zeta / f$ approaches a minimum. It is interesting that the $\zeta / f$ begins to drop indicating inflow of negative vorticity from the Caribbean Sea even though transport is still increasing (after 18 June). CO2013 show that such an inflow of negative $\zeta$ can occur as warm eddy, which contributes to increased transport, is "pushed" through the channel following the maximum trade wind.

\section{Upper-lower-layer coupling}

Using the peak Rossby wave velocity $C_{i}$ of approximately $-0.05 \mathrm{~m} \mathrm{~s}^{-1}$ (Fig. 3c), we can estimate the westward eddy velocity $C_{\text {eddy }}$ as $2 C_{i} / 3$ or approximately $-0.033 \mathrm{~m} \mathrm{~s}^{-1}$ assuming a lenslike eddy (Nof 1981). Then, the time required for the Loop's warm-water mass to peel westward and form an eddy is approximately $(3 / 2) \times R_{\text {eddy }} /\left|C_{i}\right|,(3 / 2) \times 280 \mathrm{~km} /\left|C_{i}\right|$, or 90 days, where $R_{\text {eddy }}$ is the eddy's diameter (Fig. 2). Alternatively, since the simulated eddy is not "lenslike," the $C_{\text {eddy }}$ can be estimated from Nof [1983; see also Zharkov and Nof (2008)]:

$$
C_{\text {eddy }} \approx-\beta g^{\prime}\left(h_{o}+\Delta h / 3\right) /\left[f^{2}\left(1-\zeta_{e} / f\right)\right],
$$

where $h_{o}+\Delta h$ is the thickness of the "upper layer" at the eddy's center, $h_{o}$ is the thickness of the surrounding "ambient" water, and $\zeta_{e} / f$ is the Rossby number of the eddy. Taking $\beta=2 \times 10^{-11} \mathrm{~m}^{-1} \mathrm{~s}^{-1}, f=5.8 \times 10^{-5} \mathrm{~s}^{-1}$ (at $26^{\circ} \mathrm{N}$ ), an $h_{o}$ (from the modeled $10^{\circ} \mathrm{C}$ isotherm) of approximately $400 \mathrm{~m}$, a $\Delta h$ of approximately $300 \mathrm{~m}$, and a $g^{\prime}$ of approximately $0.015 \mathrm{~m} \mathrm{~s}^{-2}$ (i.e., around a $10^{\circ} \mathrm{C}$ 

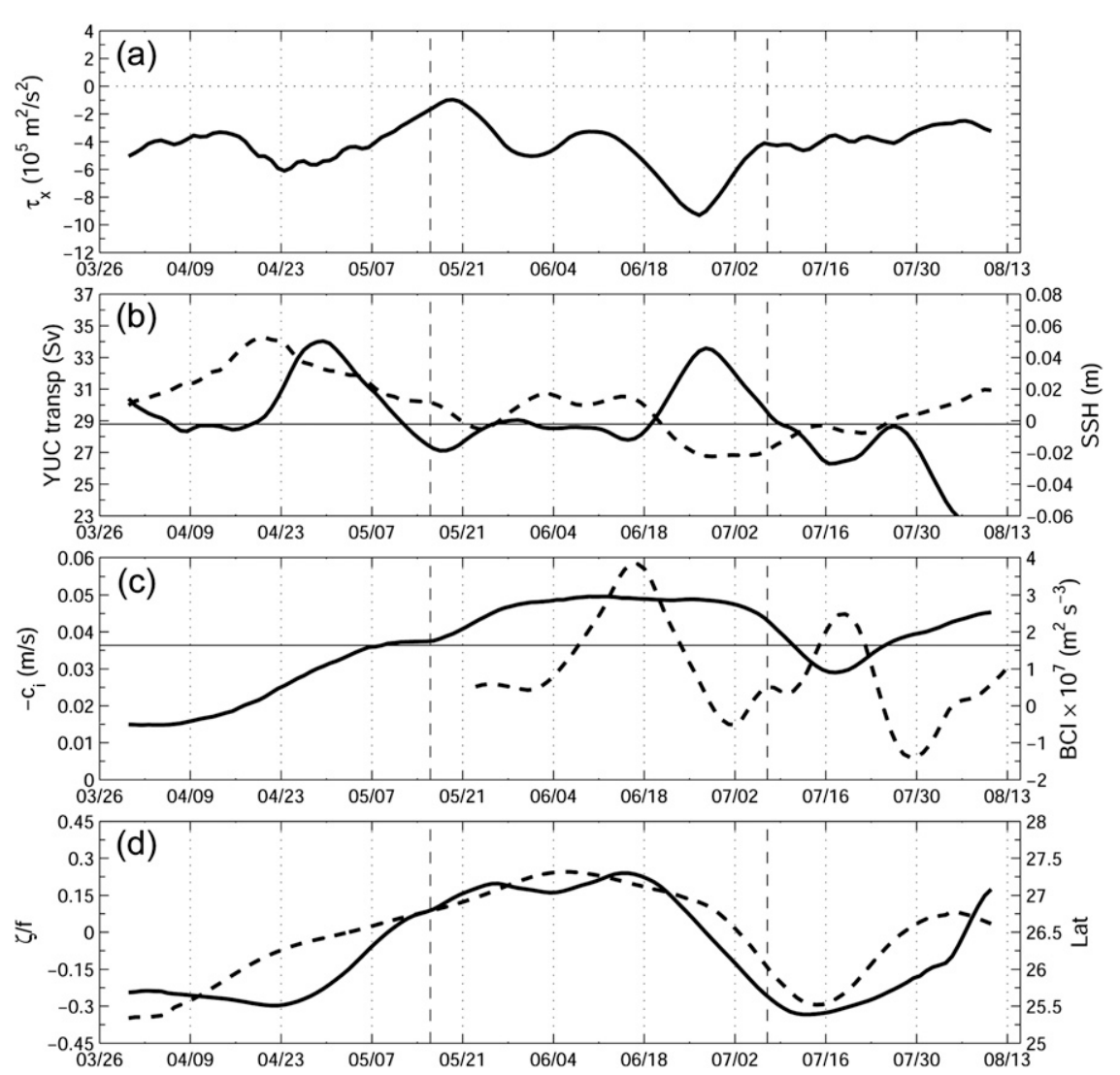

FIG. 3. (a) Ten-day-running Global Forecast System (GFS) zonal wind stress in the Caribbean Sea (averaged over $14.0^{\circ}-22.3^{\circ} \mathrm{N}, 80.3^{\circ}-88.6^{\circ} \mathrm{W}$; the result is insensitive to the averaged area as the wind is of large scale; see CO2012); (b) modeled (Exp.May15) Yucatan Channel transport (solid thick line; horizontal thin line is the mean; scale is on left $y$ axis) and eastern Gulf SSH (dashed thick line; scale is on right $y$ axis); (c) Rossby wave speed $-C_{i}$ (solid thick line; horizontal thin line is the mean; scale is on left $y$ axis) at the location marked in Fig. 2, and BCI at $z=$ $-750 \mathrm{~m}$ (dashed thick line; scale is on right $y$ axis); (d) the vorticity $\zeta$ of the inflowing Yucatan Current divided by the Coriolis parameter $f(\zeta / f$, solid thick line; scale is on left $y$ axis), and the LCNB (dashed thick line; scale is on right $y$ axis; ${ }^{\circ}$ latitude). The first vertical dash line indicates the model's starting time, and the second one marks the model's eddy-shedding time on $8 \mathrm{Jul}$.

difference between upper and lower layers); also a $\zeta_{e} / f$ of approximately 0.1 (averaged over $400 \mathrm{~m}$ and under the eddy's core defined by SSH $>0.25 \mathrm{~m}$ ), we obtain from (1) that $C_{\text {eddy }}$ is approximately $-0.05 \mathrm{~m} \mathrm{~s}^{-1}$. This gives an eddy separation time of about 65 days. Finally, $C_{\text {eddy }}$ is also estimated directly from the numerical simulation, which gives an approximate value of $C_{\text {eddy }}$ of $-0.064 \mathrm{~m} \mathrm{~s}^{-1}$, and an eddy separation time of about 50 days. Therefore, if the Yucatan inflow and Rossby wave dynamics (i.e., the Pichevin-Nof mechanism) alone were responsible for the timing of eddy shedding, then instead of 8 July the event would have occurred from near the middle of August to late September, approximately 50-90 days following the maximum transport. Why does the 3D model's eddy shed significantly earlier, by around 40-75 days, than can be predicted by the RG Rossby wave dynamics?

\section{a. Baroclinic instability and mass balance constraint}

The RG assumption of a quiescent lower layer is clearly not satisfied in the LC. There are at least two ways in which the upper and lower layers may be coupled. The first is through BCI, which can lead to cyclones that can extend deep under the LC (e.g. Chérubin et al. 2006; Oey 2008). Chérubin et al. (2006) found in their model simulations that cyclones contribute to the separation of the ring from the LC. Oey (2008) found high $\mathrm{BCI}$ growth rates off the western Florida slope and in particular north of Campeche Bank. Both works show the existence of deep cyclones at incipient eddy shedding. The second way is caused by the mass balance constraint (MBC), which stipulates that as the LC and/ or eddy expands westward, it forces a deep return flow from the western Gulf and therefore a convergence 


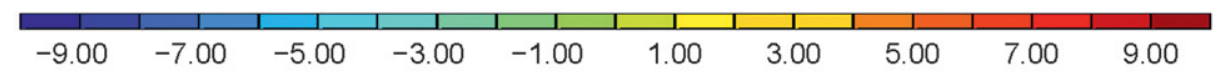

(A) May 16 - Jun 15

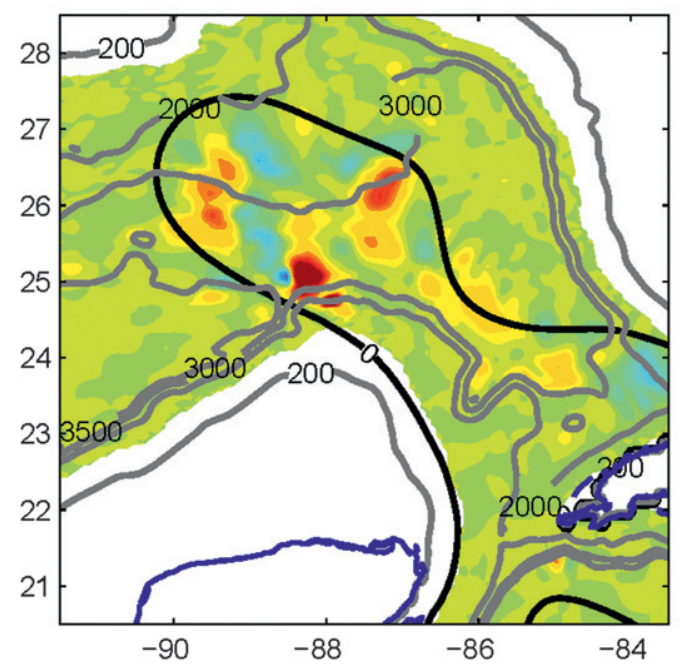

(B) Jun 01 - Jun 30

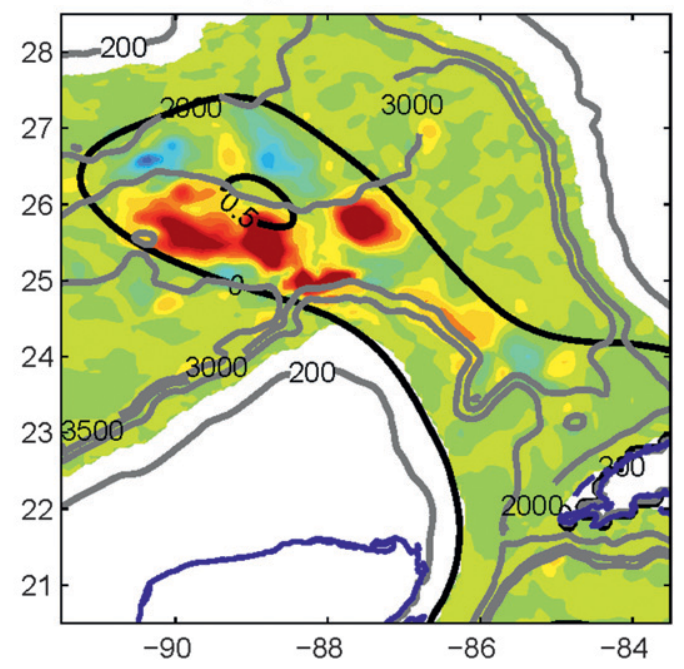

FIG. 4. The BCI $\times 10^{7}\left(\mathrm{~m}^{2} \mathrm{~s}^{-3}\right)$ at $750 \mathrm{~m}$ averaged over (a) 16 May-15 Jun and (b) 1-30 Jun. When divided by the corresponding eddy energy (kinetic + potential), the maximum (red) and minimum (blue) scales of \pm 10 correspond also to growth time scales of approximately \pm 5 days, respectively. The 0 - and 0.5 -m SSH contours (black lines) are used to indicate the Loop Current, averaged over the respective periods. Gray contours are isobaths of 200, 2000, 3000 , and $3500 \mathrm{~m}$, and thick blue contours are coastlines.

beneath the LC (below a $z$ of around $-1000 \mathrm{~m}$ ) (Chang and Oey 2011). Both processes tend to produce upwelling and upper-layer divergence in the eastern Gulf. Chang and Oey (2010) show that such divergence produces a momentum outflux from the eastern Gulf, and tends to hasten eddy shedding. We therefore conjecture that the accelerated eddy shedding in the $3 \mathrm{D}$ model is related to $\mathrm{BCI}$ and $\mathrm{MBC}$ in the eastern $\mathrm{GOM}^{2}$

To monitor divergence, we follow Ezer et al. (2003) and use the SSH (dashed curve in Fig. 3b) area averaged over the eastern Gulf (bounded by $90^{\circ} \mathrm{W}$, the southern Strait of Florida, and the Yucatan Channel, and in deepwater region where depths $>1000 \mathrm{~m}$ ). To estimate BCI, we follow Oey (2008) and calculate flow energetics over a moving $n$-day window to define the mean; the $n=15$ is chosen so that a reasonably long ( $\sim 2$ months $)$ time series may be obtained to compare with other time series in Fig. 3. The results are insensitive when $n$ is increased to 30 . We find that BCI conversion $=$ $-\left[g^{2} /\left(\rho_{o}^{2} N^{2}\right)\right]\left[\left(\left\langle u^{\prime} \rho^{\prime}\right\rangle \partial\langle\rho\rangle\right) / \partial x+\left(\left\langle v^{\prime} \rho^{\prime}\right\rangle \partial\langle\rho\rangle\right) / \partial y\right]$ [where $\langle\cdot\rangle=n$-day mean; $N^{2}=-\left(g / \rho_{o}\right)\left(d \rho_{o} / d z\right) ; x, y$, and $z$

\footnotetext{
${ }^{2}$ Other factors such as randomness of wind forcing, responses to flow-topography interaction, and strong pulses of Yucatan transport, for example, may also contribute to the accelerated shedding. Their effects are difficult to evaluate, however, making it difficult also to understand the corresponding physics.
}

denote longitudinal, latitudinal, and vertical coordinates, respectively; $u^{\prime}$ and $v^{\prime}$ are $x$ and $y$ components of the perturbation velocity, respectively; and $\rho, \rho_{o}$, and $\rho^{\prime}$ are density, reference density, and perturbation density, respectively.], dominates, as found also by Oey (2008). Maps of the 30-day-averaged BCI around 1 June and 15 June are plotted in Fig. 4, and time series of the area-averaged BCI $\left(24.5^{\circ}-26^{\circ} \mathrm{N}, 87^{\circ}-90^{\circ} \mathrm{W}\right)$ are shown in Fig. 3c.

From April through approximately mid-June, the LC is in a growing stage (Fig. 1) and the SSH in the eastern Gulf is positive on average (Fig. 3b). As described previously, during the same period, the $\left|C_{i}\right|$ increases and reaches a maximum (Fig. 3c). Thereafter (after 18 June), the Yucatan transport (and the trade wind) strengthen and peak near the end of June (Figs. 3a,b), while the SSH drops (Fig. 3b), which may be counterintuitive but is consistent with Chang and Oey (2011) that the SSH drop occurs at incipient eddy shedding because of upper-layer divergence. As discussed by these authors, the divergence in this case is partly caused by MBC: the Loop's westward expansion forced by the rapid influx of mass through the Yucatan Channel requires a return flow of cool waters to the deep portion of the eastern Gulf, thereby contributing to lower SSH. The other part is caused by BCI.

Figure 4 clearly shows that large BCIs are located under the LC on its southern side off the Campeche Bank. The large values are more widespread at the latter time (Fig. 4b) close to the shedding date than at the beginning 


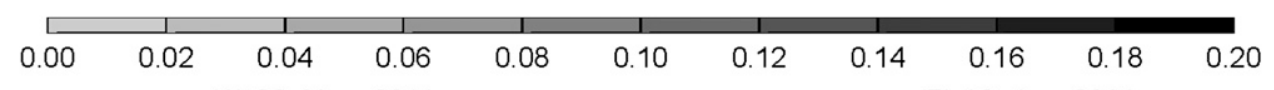

(A) 26-May-2011

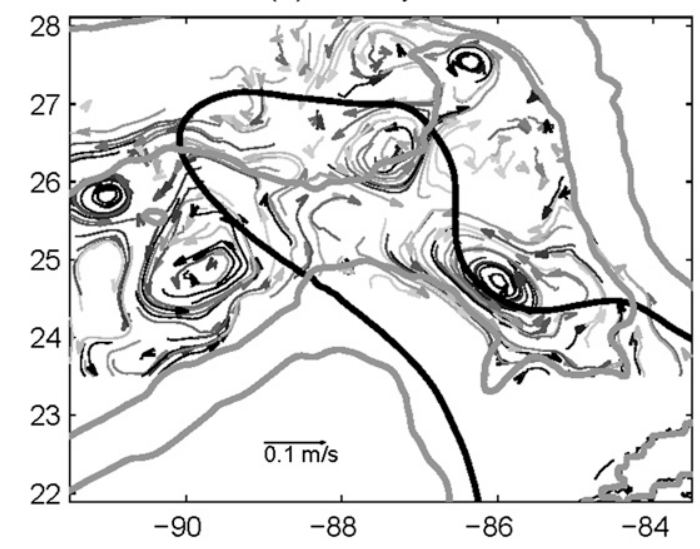

(C) 20-Jun-2011

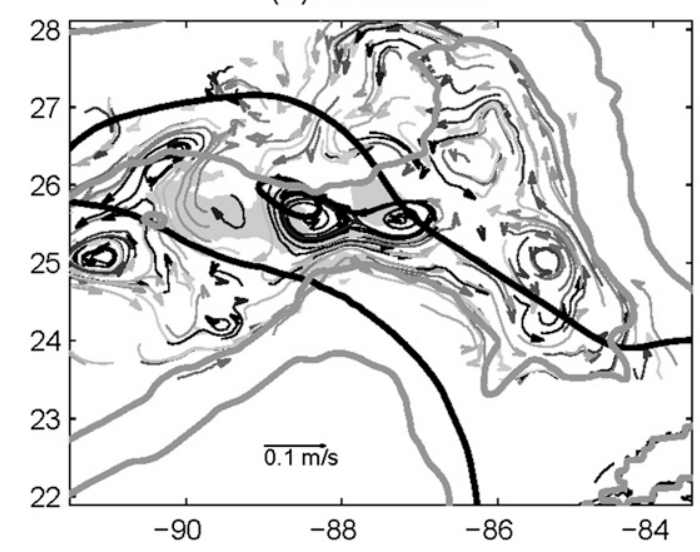

(B) 16-Jun-2011

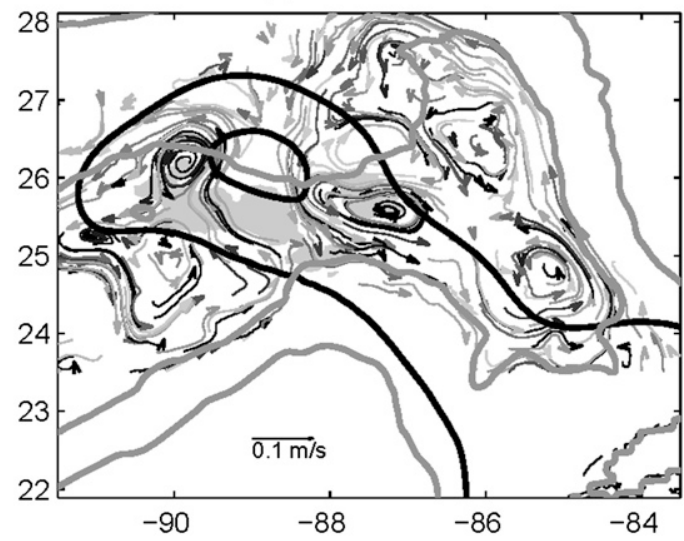

(D) 24-Jun-2011

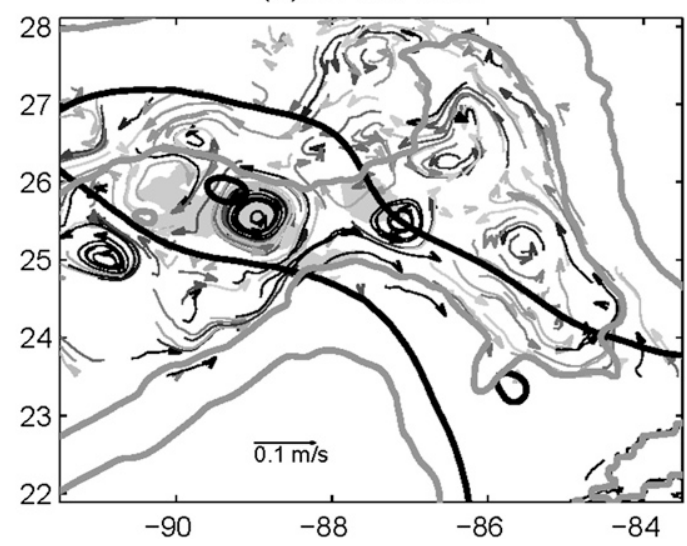

FIG. 5. Five-day-averaged velocity trajectories with the corresponding $\zeta / f$ (shaded; from 0 to 0.2 ) at $z=-1550 \mathrm{~m}$, on (a) 26 May (approximately 6-7 weeks before eddy shedding), (b) 16 Jun (approximately 2-3 weeks before eddy shedding), (c) 20 Jun, and (d) 24 Jun. Background shading in (b),(c),(d) show regions of strong BCI growth rates $\left(>4 \times 10^{-7} \mathrm{~m}^{2} \mathrm{~s}^{-3}\right.$ ) from Fig. $4 \mathrm{~b}$, covering 1-30 Jun. The LC SSH contours 0 and $0.5 \mathrm{~m}$ (black thick line) are shown, as well as the 200- and 3000-m isobaths (gray thick line).

(Fig. 4a). Figure $3 \mathrm{c}$ shows that BCI increases and becomes a maximum near mid-June. The values remain positive through the end of June approximately 1 week before the eddy shedding, and thereafter become oscillatory. As explained above, BCI can also contribute to the drop in SSH by the development of deep cyclones. The sharp rise in BCI begins near 5 June (Fig. 3c) when the LC has fully developed (as indicated by the plateau in $\left.\left|C_{i}\right|\right)$. This is consistent with the vortex instability analysis of Chérubin et al. (2006), because their analysis assumes a full-grown vortex. By comparing the dashed curves in Figs. 3b,c, BCI (Fig. 3c) rises and its peak precedes the drop in SSH (Fig. 3b), which suggests that baroclinic instability contributes to lowering the $\mathrm{SSH}$.

Deep velocity fields ( $z=-1550 \mathrm{~m}$; Fig. 5) show strong, isolated cyclones with $\zeta / f$ of approximately 0.2 and speeds of around $0.1 \mathrm{~m} \mathrm{~s}^{-1}$ and stronger, both when the
Loop is initially growing (26 May; Fig. 5a) and shortly before eddy shedding when the LC rapidly expands west-northwestward (16, 20, and 24 June; Figs. 5b,c,d). During the rapid expansion period from 16 to 20 June indicated by the steep drop in SSH (Fig. 3b) the deep eastern Gulf is dominated by a large cyclonic gyre (east of $89^{\circ} \mathrm{W}$; Figs. $5 \mathrm{~b}, \mathrm{c}$ ) that is consistent with vortex stretching of a deep layer by upwelling: $d(f+\zeta) / d t \approx$ $f_{o} \partial w / \partial z$ (cf. Chang and Oey 2011), in good agreement with the descriptions given previously when discussing Fig. 3. The large scale of the deep gyre, 350 to $450 \mathrm{~km}$, precludes its generation by BCI, for which disturbances grow at a scale of $\lambda_{\text {bci }}$ that is approximately equal to the local deformation radius $\lambda_{\text {bci }}=N H / f$, where $H$ is the vertical scale (Stone 1966). An orderof-magnitude estimate is from the Eady (1949) model, for which the most unstable wave has a growth rate of 
$\sigma_{\text {Eady }} \approx 0.3 \Delta u / \lambda_{\text {bci }}$, where $\Delta u$ is the velocity difference between the upper and lower layer, and a wavelength $\lambda_{\text {Eady }} \approx 2 \lambda_{\text {bci. }}$. Take $N \approx 5 \times 10^{-4} \mathrm{~s}^{-1}$ from deep observations (Hamilton 1990), $H \approx 1000 \mathrm{~m}$ (cf. Oey 2008), $\Delta u \approx 0.1 \mathrm{~m} \mathrm{~s}^{-1}$ [estimated from the model mean velocity profile east of $90^{\circ} \mathrm{W}$ in the eastern Gulf where isobaths >3000 m: speed@z $=(-1000 \mathrm{~m})-$ $($ speed@z) $=-2000 \mathrm{~m}]$, and $f=5.8 \times 10^{-5} \mathrm{~s}^{-1}$ (at $26^{\circ} \mathrm{N}$ ), we obtain an Eady growth time scale $1 / \sigma_{\text {Eady }}$ of around 4 days in good agreement with Fig. 4 , and $\lambda_{\text {Eady }}$ of approximately $20 \mathrm{~km}$. The latter length scale is much smaller than the deep gyre scale but is comparable to the cyclone scales of around $20-100 \mathrm{~km}$ seen in Figs. 5 b,c. ${ }^{3}$ These results suggest that the deep cyclonic gyre is primarily induced by the MBC, forced by the Loop's westward expansion, while embedded in it are small eddies caused by BCI. An example of the BCI and cyclones that appear to contribute to an accelerated shedding is also seen in Figs. 5b,c,d. On 16 June, a strong cyclone $\left(25.6^{\circ} \mathrm{N}, 87.2^{\circ} \mathrm{W}\right)$ develops north of Campeche Bank coincident with the BCI peak at the same location in Fig. 4b. On 20 June, the cyclone splits into a dipole of two cyclones, and the leading, larger cyclone rapidly moves westward in concert with the expanding LC while the smaller one is left nearly stationary off the Campeche Bank under the thinning neck of the LC (see 24 June plot in Fig. 5d). Figure 4b shows that BCI remains locally strong during the entire splitting process. It is a chicken-and-egg relationship, however, to infer if the BCI and the corresponding cyclones induce rapid westward expansion of the Loop, or if the large-scale expanding Loop leads to BCI and cyclones. We postulate that it is the latter, but that there exists a positive feedback in which BCI and cyclones accelerate the expansion but at small scales, the same way as the gyrescale upwelling by MBC is coupled to and also accelerates the expansion.

\section{b. EOFs using AVISO and a $3 D$ model, and comparison with a reduced-gravity model}

The above provides an intuitive inference that upperlower coupling leads to accelerated eddy shedding; a more quantitative assessment is now given. CO2013 analyzed EOFs based on satellite SSH data (AVISO) from 1993 to 2010. They found that the two leading modes, which account for $47 \%$ of the total variance, represent LC growth, westward expansion, eddy shedding, and retraction, especially during the summer-tofall period-of-interest. This Loop Current Cycle (Chang

\footnotetext{
${ }^{3}$ The eddies are larger because they presumably are the finiteamplitude products of the baroclinically unstable disturbances.
}

and Oey 2011) is shown to agree well with an RG model, which can be explained by the Pichevin-Nof mechanism and the theory of Reid (1972). Since EOFs are not dynamic modes (Kundu et al. 1975), one cannot interpret EOFs $1+2$ as being equivalent to RG. However, from the analysis of CO2013, it seems clear that EOFs $1+2$ primarily describe the upper-layer variability of the LC; this we assume a priori and we will provide supporting evidence below using long-term model experiments. It follows then that a large part of variability caused by upper-lower-layer coupling is contained in the higher EOF modes. Figure 6 shows AVISO EOFs $3+4$, which explain $13 \%$ and $8 \%$ of the total variance, respectively. Unlike EOFs $1+2$ (CO2013), these higher modes do not have a significant seasonal signal. Instead, the principal component time series fluctuate at unpredictable time intervals. Their eigenvectors show multipolar patterns similar to those found by Chérubin et al. (2006) and Oey (2008). However, the temporal resolution of AVISO ( $~ 10$ days) does not allow interpretations of the patterns as being caused by BCI, and all that can be said is that they represent some complex physics of smaller scales than the LC expansion and retraction processes of the upper layer. To see how these higher EOF modes affect eddy shedding, we select shedding events from AVISO for eddies with diameters larger than $200 \mathrm{~km}$ as measured by the SSH 0.1-m contour. We then compare the actual shedding dates with those obtained using only 1) EOF modes $1+2$ and 2) EOF modes $1+2+3$ (Fig. 7). Twenty "large" eddies were identified according to our criterion but as some eddy-shedding events could not be identified using only EOFs $1+2$, only 13 events remain. The shedding dates for EOFs $1+2$ lag the actual dates by approximately $15-70$ days with a mean of 37 days (Fig. 7), while those for EOFs $1+2+3$ lag the actual dates by approximately $7-36$ days with a mean of 19 days. Including the higher EOF mode 3 accelerates eddy shedding. The mean delay (lag time) of 37 days for EOFs $1+2$ agrees well with the above estimate for the 2011 summer shedding of the mean delay of around 40 days assuming that RG Rossby wave dynamics alone are responsible for the "peeling off" of the eddy from the LC.

A similar analysis is conducted using the 22-yr freerunning 3D model of $\mathrm{CO} 2012$ forced by the CCMP wind. The model's EOFs $1+2$ have a strong seasonal cycle accounting for approximately $60 \%$ of the total variance, similar to (but stronger than) those observed (CO2013); the spatial patterns (eigenvectors) are also similar, and represent LC growth, westward expansion, eddy shedding, and retraction with a strong summer-tofall component. There are now 21 eddy-shedding events (because of the longer time series). As shown in Fig. 8 (top), the shedding dates for EOFs $1+2$ now lag the 

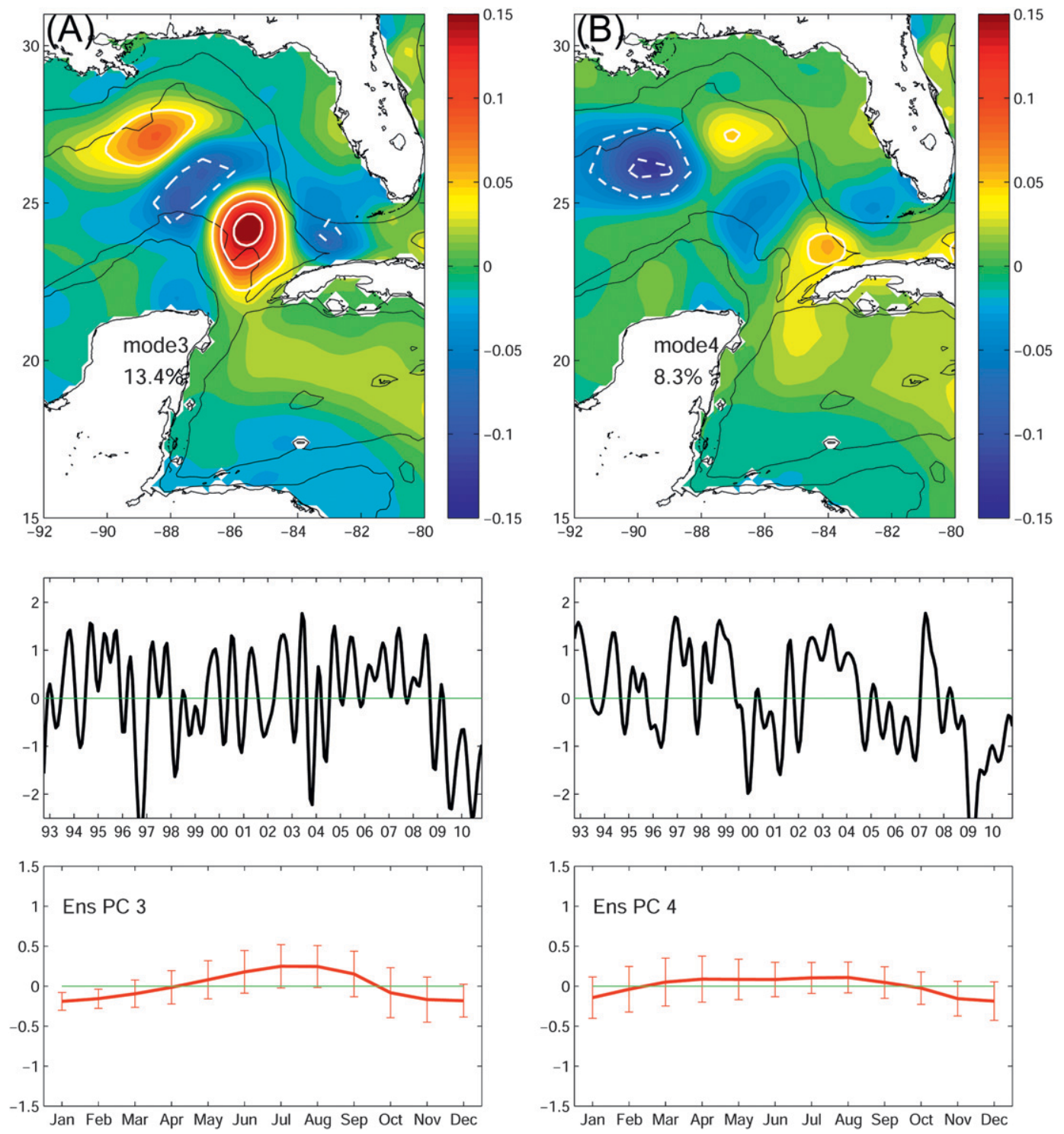

FIG. 6. AVISO SSH (1993-2010) EOF (a) mode-3 and (b) mode-4: (top) eigenvectors (m), (middle) principal components ( $x$ axis shows the year), and (bottom) corresponding monthly composite with standard error bars, both dimensionless. As in CO2013, the annual cycle of steric height has been removed before the EOF analysis.

actual dates by a mean of 50 days (which may be compared with the mean of 37 days for AVISO), while those for EOFs $1+2+3$ lag the actual dates by a mean of 34 days (19 days for AVISO). An example of the differences of eddy shedding in the three cases is given in Fig. 8 (bottom), which shows how the shedding process for EOFs $1+2$ appears to be "more viscous" than for EOFs $1+2+3$, which in turn appears more viscous when compared with the actual shedding. The lags are longer in the model, perhaps because the observed modes $1+2$ are "richer" containing other variability, while models are biased with a higher percentage of the purely upper-layer, Rossby wave dynamics. However, the trends agree with observations. In conclusion, by successively including higher modes, 1) EOFs $1+2+3$, and 2) the total time series, the shedding time is always accelerated (for all of the observed and modeled shedding cases - note that this fact is not guaranteed a priori) relative to a hypothetical Loop that contains only EOFs $1+2$.

We now compare the shedding times of an RG model forced by the same 22-yr CCMP wind stress used for the 3D model. By examining the RG "animation," we observe that its shedding characteristics share visual similarities with those of the 3D EOFs $1+2$ (Fig. 8b, dotted line): they both show prolonged shedding processes and the modeled LC appears to be "viscous." We now show 


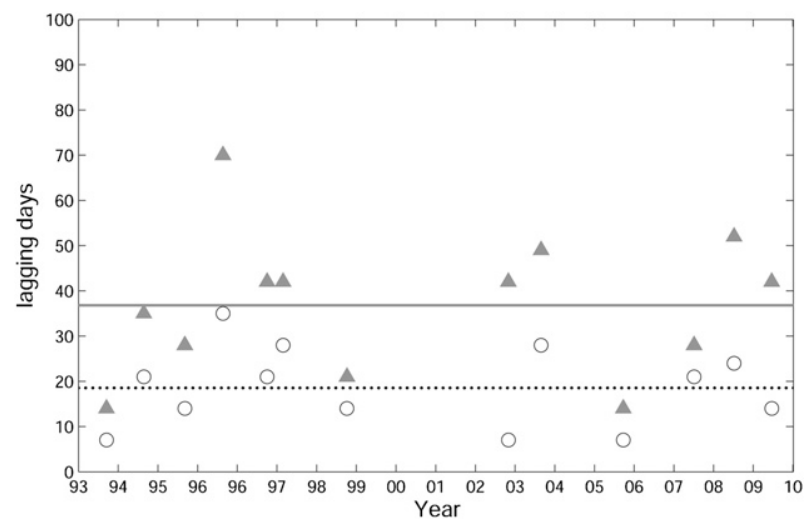

FIG. 7. Time lags (days) of eddy shedding compared with the observed shedding dates when only EOF modes $1+2$ [solid triangles; solid line is the mean of 37 days (standard error $= \pm 4.4$ )] are included, and when only EOF modes $1+2+3$ [open circles; dashed line is the mean of 19 days (standard error $= \pm 2.5$ )] are included. Note that not all eddies are included in this comparison because some eddy sheddings are not discernible when only modes $1+2$ are included

that the RG eddy shedding also lags the full 3D model shedding. Unlike the case of comparing model (or observed) shedding and its own EOF modes, there is not a one-and-one correspondence between the shedding of the RG and $3 \mathrm{D}$ models, and the comparison is not as straightforward. However, the analyses presented in CO2012 and CO2013, as well as the above analysis for the present 2011 realistic case (Fig. 3), provide evidence that eddy shedding generally follows the peak in Yucatan transport. This is true for both the RG and 3D models. ${ }^{4}$ We therefore composite both 3D and RG Yucatan transports about their respective shedding dates (Fig. 9; cf. Chang and Oey 2011). On average the 3D and RG models shed eddies 30 and 90 days after their maximum transports, respectively. The difference of 60 days agrees well with the long-term mean 50-day lag (Fig. 8) between the EOFs $1+2$ from the 3D models and the actual shedding dates. That the lag is a little shorter ( $\sim 10$ days) for the $3 \mathrm{D}$ EOFs $1+2$ is also consistent, since the latter may not only account for upper-layer variability.

Figure 10 gives a schematic summary of the above ideas. Here, the leading EOFs $1+2$ represent primarily growth and the Rossby wave peeling process of the upper layer of the LC (Fig. 10a). The remaining higher modes account for coupled upper-lower processes including $\mathrm{BCI}$ and the coupling between the

\footnotetext{
${ }^{4}$ There are no long-term (decadal) Yucatan transport measurements. However, because of the strong wind-forced transport response especially from summer to fall, this also appears to be true from the satellite analysis (CO2012, CO2013).
}

western and eastern GOM as the LC expands westward or eddies propagate across the basin (i.e., MBC; Fig. 10b).

\section{Conclusions}

In this paper, we study the dynamics of an eddyshedding event of the LC in July 2011 using the Princeton Ocean Model and observations. Satellite observations are assimilated into the model to initialize a forecast (without assimilation), which then produces eddy shedding as it is also observed. We then analyze in detail the dynamical process of this specific realistic case to test a hypothesis by $\mathrm{CO} 2012$ that eddy shedding may be caused by the weakening of the Caribbean Sea's trade wind. The conclusions are as follows.

1) In March-August 2011, there is a strong, negative correlation between the zonal wind stress in the Caribbean Sea and Yucatan Channel transport into the GOM. The transport agrees in amplitude and phase with that reported by Rousset and Beal (2010) based on 5-yr ship observations and appears to be part of the biannual cycle that is closely linked to the trade wind in the Caribbean Sea, as has been previously found by $\mathrm{CO} 2012$.

2) An eddy-shedding event is observed in July in both model and satellite SSH concurrent with the weakening of the transport and trade wind from their summer peaks, which in 2011 occurred near the end of June. This scenario may be explained by the Pichevin-Nof mechanism that suggests that eddy shedding is fundamentally an upper-layer process in which westward peeling of the grown Loop by Rossby wave overcomes the Loop's growth by the Yucatan transport.

3) However, Rossby wave dynamics alone predict a slow eddy-shedding process and cannot account for the accelerated shedding seen in the 3D model analysis.

4) SSH drop and baroclinic instability are diagnosed over the LC around 2-3 weeks prior to eddy shedding; they lead to upper-lower-layer coupling and upper-flow divergence in the LC, hence zonal momentum outflux, which tends to hasten eddy shedding.

5) Analyses of long-term satellite altimetry and 3D model data show that by retaining only the two leading EOF modes, eddy-shedding times are delayed by around 37-50 days on average. Comparison with eddy shedding from an RG model suggests that these leading modes $1+2$ primarily represent shedding by the Pichevin-Nof mechanism, and higher modes contribute through upper-lower-layer coupling including $\mathrm{BCI}$ and $\mathrm{MBC}$, which accelerate eddy shedding. 

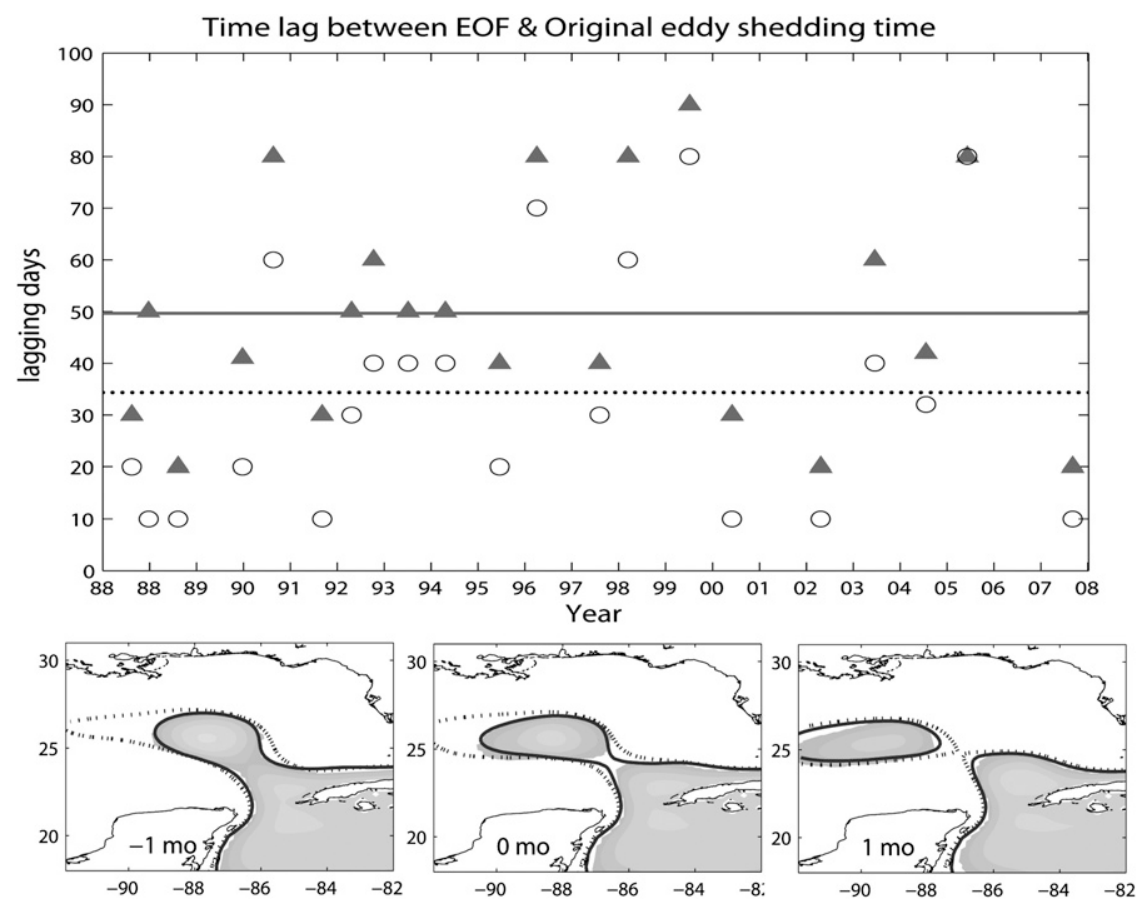

FIG. 8. (top) Time lags (days) of eddy shedding compared with the shedding dates of the full 3D model when only EOF modes $1+2$ [solid triangles; solid line is the mean of 50 days (standard error $= \pm 4.8$ )] are included, and when only EOF modes $1+2+3$ [open circles, dotted line is the mean of 34 days (standard error $= \pm 5.1$ )] are included. Not all eddies are included because some eddy sheddings are not discernible when only modes $1+2$ are included. (bottom) An example of an eddy-shedding event (April 1993; -1, 0, and +1 month) for the 3D model (shaded for positive SSH) and for the hypothetical models with EOF modes $1+2+3$ and EOF modes $1+2$, solid and dotted zero contours, respectively.

The MBC requires a compensating deep inflow into the eastern Gulf as the LC rapidly expands westward prior to the shedding of an eddy (Chang and Oey 2011). The present study suggests that the MBC gives rise to a deep (eastern) basin-scale response consisting of a

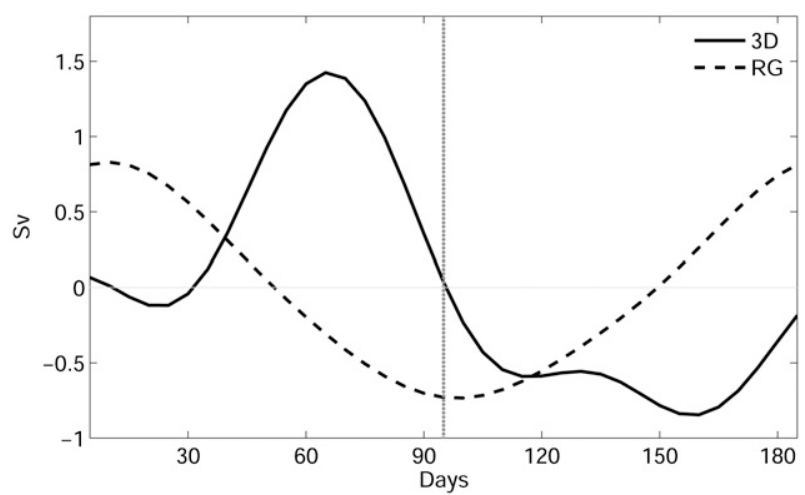

FIG. 9. Yucatan transport anomalies (for clarity, the RG-anomaly is multiplied by 1.5); composited from $22 \mathrm{yr}$ of $3 \mathrm{D}$ and $\mathrm{RG}$ model data. There are 29 3D-model eddies and 37 RG-model eddies. The composites are computed about each model's eddy-shedding times (vertical dotted line); see text for details. cyclonic recirculation gyre, while BCI produces smallerscale eddies which are embedded within the gyre (Fig. 5). It would be interesting to detect and analyze these processes in observations.

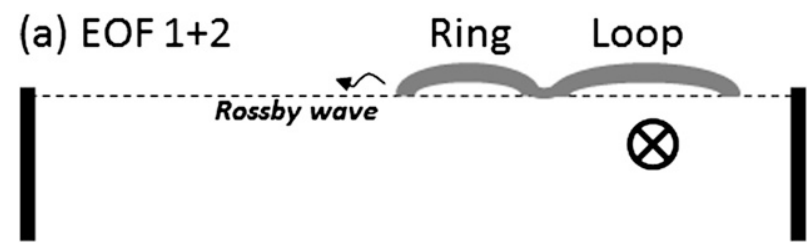

(b) All

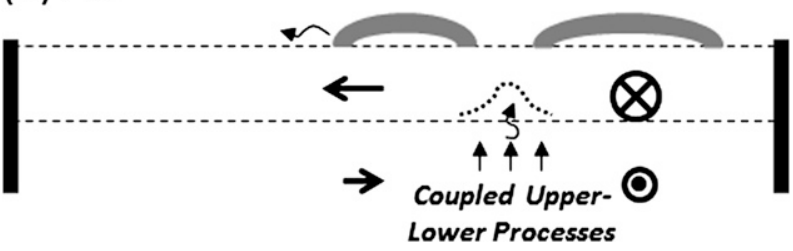

FIG. 10. A schematic of effects of EOF (a) modes $1+2$, and (b) all modes on Loop Current eddy shedding. The coupled upperlower-layer processes indicated in (b) include contributions by the $\mathrm{MBC}$ and $\mathrm{BCI}$ described in text. 
Acknowledgments. Comments from two anonymous reviewers helped improve the manuscript. We acknowledge support from the Bureau of Ocean Energy Management Contract M08PC20007.

\section{APPENDIX}

\section{List of Frequently Used Acronyms}

Three-dimensional (primitive equation model) (3D)

Archiving, Validation, and Interpretation of Satellite

Oceanographic data (AVISO)

Baroclinic instability (BCI)

Cross-calibrated multi-platform (wind) (CCMP)

Empirical orthogonal function (EOF)

Gulf of Mexico (GOM)

Loop Current (LC)

Loop Current northern boundary (LCNB)

Mass balance constraint (MBC)

Reduced-gravity (model) (RG)

Sea surface height $(\mathrm{SSH})$

Sea surface height anomaly (SSHA)

\section{REFERENCES}

Candela, J., S. Tanahara, M. Crepon, B. Barnier, and J. Sheinbaum, 2003: Yucatan Channel flow: Observations versus CLIPPER ATL6 and MERCATOR PAM models. J. Geophys. Res., 108, 3385, doi:10.1029/2003JC001961.

Chang, Y.-L., and L.-Y. Oey, 2010: Why can wind delay the shedding of Loop Current eddies? J. Phys. Oceanogr., 40, 2481-2495.

—_, and _- 2011: Loop Current Cycle: Coupled response of the Loop Current with deep flows. J. Phys. Oceanogr., 41, 458-471.

— and - 2012: Why does the Loop Current tend to shed more eddies in summer and winter? Geophys. Res. Lett., 39, L05605, doi:10.1029/2011GL050773.

— and - 2013: Loop Current growth and eddy shedding using models and observations: Numerical process experiments and satellite altimetry data. J. Phys. Oceanogr., 43, 669-689.

Chérubin, L. M., Y. Morel, and E. P. Chassignet, 2006: Loop Current ring shedding: The formation of cyclones and the effect of topography. J. Phys. Oceanogr., 36, 569-591.

Eady, E. T., 1949: Long waves and cyclone waves. Tellus, 1, 33-52.

Ezer, T., L.-Y. Oey, H.-C. Lee, and W. Sturges, 2003: The variability of currents in the Yucatan Strait: Analysis of results from a numerical ocean model. J. Geophys. Res., 108, 3012, doi:10.1029/2002JC001509.

Hamilton, P., 1990: Deep current in the Gulf of Mexico. J. Phys. Oceanogr., 20, 1087-1104.

Kundu, P., J. S. Allen, and R. L. Smith, 1975: Modal decomposition of the velocity field near the Oregon coast. J. Phys. Oceanogr., 5, 683-704.

Le Hénaff, M., V. H. Kourafalou, Y. Morel, and A. Srinivasan, 2012: Simulating the dynamics and intensification of cyclonic Loop Current Frontal Eddies in the Gulf of Mexico. J. Geophys. Res., 117, C02034, doi:10.1029/2011JC007279.

Lin, Y., R. J. Greatbatch, and J. Sheng, 2009: A model study of the vertically integrated transport variability through the Yucatan
Channel: Role of Loop Current evolution and flow compensation around Cuba. J. Geophys. Res., 114, C08003, doi:10.1029/2008JC005199.

Molinari, R. L., S. Baig, D. W. Behringer, G. A. Maul, and R. Legeckis, 1977: Winter intrusions of the Loop Current. Science, 198, 505-507.

Morey, S. L., P. J. Martin, J. J. O'Brien, A. A. Wallcraft, and J. Zavala-Hidalgo, 2003: Export pathways for river discharged fresh water in the northern Gulf of Mexico. J. Geophys. Res., 108, 3303, doi:10.1029/2002JC001674.

Nof, D., 1981: On the $\beta$-induced movement of isolated baroclinic eddies. J. Phys. Oceanogr., 11, 1662-1672.

, 1983: On the migration of isolated eddies with application to Gulf Stream rings. J. Mar. Res., 41, 399-425.

_ 2005: The momentum imbalance paradox revisited. J. Phys. Oceanogr., 35, 1928-1939.

Oey, L.-Y., 1996: Simulation of mesoscale variability in the Gulf of Mexico. J. Phys. Oceanogr., 26, 145-175.

2008: Loop Current and deep eddies. J. Phys. Oceanogr., 38, 1426-1449.

— P. Hamilton, and H.-C. Lee, 2003: Modeling and data analyses of circulation processes in the Gulf of Mexico. U.S. Department of the Interior Minerals Management Service Rep. MMS 2003-074, 129 pp.

— , T. Ezer, G. Forristall, C. Cooper, S. DiMarco, and S. Fan, 2005: An exercise in forecasting Loop Current and eddy frontal positions in the Gulf of Mexico. Geophys. Res. Lett., 32, L12611, doi:10.1029/2005GL023253.

Pichevin, T., and D. Nof, 1997: The momentum imbalance paradox. Tellus, 49, 298-319.

Reid, R. O., 1972: A simple dynamic model of the Loop Current. Contributions on the Physical Oceanography of the Gulf of Mexico, L. R. A. Capurro and J. L. Reid, Eds., Texas A\&M University Oceanography Series, Vol. 2, Texas A\&M University, 157-159.

Romanou, A., E. P. Chassignet, and W. Sturges, 2004: Gulf of Mexico circulation within a high-resolution numerical simulation of the North Atlantic Ocean. J. Geophys. Res., 109, C01003, doi:10.1029/2003JC001770.

Rousset, C., and L. Beal, 2010: Observations of the Florida and Yucatan Currents from a Caribbean cruise ship. J. Phys. Oceanogr., 40, 1575-1581.

Schmitz, W. J., Jr., 2005: Cyclones and westward propagation in the shedding of anticyclonic rings from the Loop Current. Circulation in the Gulf of Mexico: Observations and Models, Geophys. Monogr., Vol. 161, Amer. Geophys. Union, 241-261.

Sheinbaum, J., J. Candela, A. Badan, and J. Ochoa, 2002: Flow structure and transport in the Yucatan Channel. Geophys. Res. Lett., 29, 1040, doi:10.1029/2001GL013990.

Sheng, J., and L. Tang, 2003: A numerical study of circulation in the western Caribbean Sea. J. Phys. Oceanogr., 33, 2049-2069.

Stone, P. H., 1966: On non-geostrophic baroclinic stability. J. Atmos. Sci., 23, 390-400.

Sturges, W., 1994: The frequency of ring separations of Loop Current. J. Phys. Oceanogr., 24, 1647-1651.

— and R. Leben, 2000: Frequency of ring separations from the Loop Current in the Gulf of Mexico: A revised estimate. J. Phys. Oceanogr., 30, 1814-1819.

Vukovich, F. M., 1988: Loop Current boundary variations. J. Geophys. Res., 93 (C12), 15 585-15 591.

Yin, X.-Q., and L.-Y. Oey, 2007: Bred-ensemble ocean forecast of Loop Current and eddies. Ocean Modell., 17, 300-326.

Zharkov, V., and D. Nof, 2008: Agulhas ring injection into the South Atlantic during glacials and interglacials. Ocean Sci., 4, 223-237. 